\title{
Kartagener Syndrome
}

National Cancer Institute

\section{Source}

National Cancer Institute. Kartagener Syndrome. NCI Thesaurus. Code C84797.

A rare autosomal recessive inherited syndrome characterized by situs inversus,

bronchiectasis, and chronic sinusitis. There is a defect in the function of the cilia that line the respiratory tract. 